The paper is devoted to the problem of increasing the efficiency of melon processing under limited production automation. Measures for equipment modernization should be carried out in accordance with the operation rules of each individual unit. In production conditions, all equipment, without exception, undergoes this process, while the corresponding documentation is drazon up, confirming the implementation of modernization within a certain time frame.

In a competitive market environment, product quality is a causal factor for the sharp increase in risks for food industry enterprises. To produce quality and competitive products, you need equipment that helps to reduce costs. The disadvantages of most melon peeling designs are size instability in the thickness of the rind. The paper presents a solution to this drawback. This was achieved by changing the sharpening angle of the rind cutting knife.

Research has been carried out to study the texture properties of "Mirzachulskaya" and "Raduzhnaya" melons. And also experiments on melon peeling based on the planning matrix of mathematical modeling. Based on the experiments, a model of the peeling process was constructed.

The key factors to limit peeling waste were optimized. Calculations of the optimized parameters yielded the cutting knife sharpening angle of 40 degrees, a roller gap of $9 \mathrm{~mm}$, as well as an average force applied of 1,375 N.m. The data obtained can be used as a basis for the modernization of this machine for other melon varieties

Keywords: melon, processing, equipment modernization, cutting knife, peeling process, texture properties, competitive products, cleaning machine, mathematical model for melon peeling, planning matrix
UDC 66-962

DOI: $10.15587 / 1729-4061.2021 .235812$

\title{
DEVELOPMENT OF A MATHEMATICAL MODEL FOR THE PROCESS OF MODERNIZATION OF A MELON CLEANING MACHINE
}

Marzhan Kizatova

Corresponding author

$\mathrm{PhD}$, Head of Laboratory

Laboratory of Primary Processing of Plant Raw Materials**

E-mail: marzhany87@mail.ru

Alibek Baikenov

Head of Laboratory*

Nurzhan Muslimov

Doctor of Technical Sciences, Director*

Kadyrbek Baigenzhinov

Researcher*

Zhazira Yessimova

Researcher*

*Laboratory of Deep Processing of Crop Products** **Astana branch of "Kazakh research Institute of processing and food industry" LLP Al-Farabi ave., 47, Nur-Sultan, Republic of Kazakhstan, 010000

Received date 28.04.2021 Accepted date 09.06.2021 Published date 30.06.2021
How to Cite: Kizatova, M. E., Baikenov, A. O., Muslimov, N. Z., Baigenzhinov, K. A., Yessimova, Z. A. (2021). Development of a mathematical model for the process of modernization of a melon cleaning machine. Eastern-European Journal of Enterprise Technologies, 3 (11 (111)), 88-95. doi: https://doi.org/10.15587/1729-4061.2021.235812

\section{Introduction}

One of the main reasons for the need to modernize equipment for processing and cleaning agricultural products of plant origin is that certain equipment was tested only on certain varieties. Due to the difference in climate and cultivation conditions of the same varieties of melons, they have different quality indicators. So the paper examines two melon varieties of one genotype grown in different conditions. This paper discusses the structural features of the two "Mirzachulskaya" and "Raduzhnaya" melon varieties of the same genotype "Torpedo". Research has been carried out to study the constituent parts of the melon (rind, pulp and seeds), as well as melon density in different layers, and the effort that must be made to cut the rind and pulp has been determined.

The most effective is the modernization of the cutting tool (knife) by changing the sharpening angle of the knife, as well as determining the forces applied to the knife to remove the melon rind. The parameters of the knife sharpening angle, forces and roller gap were determined by means of optimization and construction of a mathematical model.
Research in this direction will make it possible to use more and more melon varieties, as well as provide an opportunity to test cleaning on other types of crop products.

\section{Literature review and problem statement}

Melon (Cucumis melo L.) is one of the most consumed fruit crops worldwide and belongs to the Cucurbitaceae family [1]. Over the past ten years, the annual melon production has hovered around about 30 million tons per year, with China being the main producer. Melon is described as an important source of phytochemicals with potential health benefits, often attributed to its high antioxidant activity, mainly due to phenolic fraction [2], as well as amino acids, organic acids, and other polar compounds [3]. Melon has extensive genotypic and phenotypic variations, which are divided into several intraspecific classifications [4].

Growing melons is not very labor-intensive, and the plants themselves are relatively unpretentious to the growing conditions, they are able to give a large harvest of not only delicious, but also very useful fruits. However, it should 
be noted that every year in farms, a significant part of the harvest is made up of damaged products, the consumption of fresh melons is limited by the time of their receipt, and during storage, the nutritional value is significantly reduced due to the breakdown of melon monosaccharides.

Using melon processing, it is possible to get high-quality long-term storage products. Today, melon is successfully processed into melon honey, marshmallows, jams and sweet canned vegetables. All the products obtained are in high demand, which makes it necessary to expand their range. However, as the analysis of the domestic market of fruit and vegetable products shows, there are practically no domestic melon processing products at stores. This is due to a number of reasons. Enterprises are not interested in processing melon crops, in particular, melon, due to the high labor intensity and low mechanization of the process (the lack of universal peeling and cutting machines).

The introduction of advanced technologies based on the integrated mechanization of the processing process will not only facilitate the work of melon growers, but also increase its productivity, as well as reduce production costs.

In most cases, significant system failures are noticable. However, if the installation has not been upgraded for a long time, it may fail altogether. The equipment modernization project is the basis for starting work on improving the performance of a particular machine. The normalization of work is created based on a pre-planned schedule for the modernization process.

Modernization of equipment is the most important aspect in technological development. Without being modernized, equipment malfunctions or becomes inoperable. As a result, the installation should certainly be subjected to repair work. Any measure aimed at improving equipment must be carried out in accordance with the basic operation rules of each individual machine.

To change this situation, it is necessary to create a modern production and technological base of the food and processing industry on a new basis.

To ensure the high competitiveness of national products, it is necessary to develop innovative technologies, apply resource-saving equipment.

Machinery and equipment, which make up about $43 \%$ of the total value of fixed assets, whose service life varies depending on the type, require constant updating in conditions of accelerated depreciation, as is done in industrialized countries. Accelerated depreciation of the active part of fixed assets ensures high competitiveness of food companies and allows them to diversify production to occupy new markets for their products in various countries of the world.

Modernization of the technical and technological base of food industry enterprises using modern types of equipment will increase the depth of processing of agricultural raw materials and thereby reduce their negative impact on the environment, significantly increasing the profitability of production [5].

The sustainable development of the machine-building industry for the food and processing industry provides an opportunity to expand the product range at lower costs, expands the range of domestic companies (especially in small and medium-sized businesses), creates a stable demand for research and development, supporting and stimulating the growth of the technological development of the economy.

However, to date, there is no clearly formulated and established classification of machines and devices for peeling and cutting melon fruits into pieces. The lack of clarity in the classification and choice of the type of these machines creates certain difficulties for the theoretical and computational justification of them when processing melons.

Considering the fundamental differences in the production technologies of these products, they have in common the process of melon cleaning, which is implemented at processing enterprises mainly with the help of manual labor or rather primitive mechanized means for cleaning this crop. Since the output of products falls mainly on the period of melon maturation, the task of mechanizing the process of its cleaning, in order to achieve a number of goals, becomes necessary and urgent. These goals are reducing the level of manual labor, minimizing production costs, reducing the loss of a valuable part of the pulp during cleaning, reducing raw material losses during storage by accelerating processing and eliminating the need for accumulation in storage, increasing the productivity of lines.

At the moment, the technology of removing the outer cover from melon fruits is based on manual labor, and the existing design and technological solutions of machines for cleaning fruits from the rind do not provide effective and high-quality processing of melons [6, 7].

The main issues that arise when cleaning melons is to separate the peel (epidermis layer) from the pulp (the main parenchyma), as well as remove the internal contents (placenta with seeds) from the seminal cavity. It should also be noted that in addition to cleaning, an important task is to reduce the time interval from cleaning to cutting the cleaned blanks, that is, to reduce the oxidation time and juice loss during processing.

In $[8,9]$, melon peeling as a preliminary and main stage of processing is currently carried out by mechanical, chemical and thermal methods [8,9]. Although each method has both advantages and disadvantages, mechanical methods are mostly preferred, since they allow keeping the edible parts of the products fresh and undamaged [10]. The main disadvantages of mechanical methods are rather low flexibility and high losses of the valuable part of the fruit. Many researchers have tried to improve the mechanical peeling methods [11]. Despite these attempts, there are still some limitations, which require additional research.

When mechanically cleaning fruits and vegetables, the most common methods are abrasive or cutting tools. Machines and apparatuses that use cutting tools for peeling are of periodic and continuous types. The removed rinds occur during the rotation of the roller or cylinder. Cutting tools, i.e. knives, are widely used for peeling apples, carrots, and potatoes [12]. Despite the high performance, the main limitation is the load sensitivity and the large amount of edible waste due to the low flexibility [13,14].

To improve the cleaning method and determine the operational and design parameters of the melon cleaning machine, it is necessary to modernize the equipment that is widely used everywhere, as well as to conduct a number of studies on the structural and mechanical properties of melons of the "Raduzhnaya" and "Mirzachulskaya" varieties, and to study the shape and geometric features.

\section{The aim and objectives of the study}

The aim of the study is adapting the melon cleaning machine of the brand VOE.201, due to the modernization of 
the cutting tool itself. Research in this area will provide an opportunity for further modernization of equipment in this industry. It will be possible to clean melons without being limited to one genotype.

To achieve the aim, the following objectives were set:

- to conduct research on the textural properties of melons of two varieties;

- to make an analysis of the operation of melon cleaning equipment, to investigate the peeling mechanism;

- to build a mathematical model for melon peeling.

\section{Materials and methods}

The texture studies were conducted using puncture and compression assessments performed with a TA.XT plus texture analyzer (Texture Technologies Corp., Scarsdale, NY, USA) equipped with a $50 \mathrm{~kg}$ load sensor, the test results were analyzed using the Exponent TE32 program (v. 5. 06.0, Texture Technologies Corp., Scarsdale, NY, USA). For piercing and squeezing, a test was performed on the peel side (peel removed) of each of five $2 \times 2 \times 2 \mathrm{~cm}$ square melon flesh cubes. Three samples were taken for each variety. The study is intended for laboratory equipment. Melon shelf life is 4-5 months before the experiment, and after cleaning it can be stored in a refrigerator for a maximum of 5 days.

To test the puncture, a cylindrical probe with a flat stainless steel head of $5 \mathrm{~mm}$ in diameter was taken. A total length of $6 \mathrm{~mm}$ and a speed of $1 \mathrm{~mm} / \mathrm{s}$ after contact with the sample [15]. The samples were compressed twice to $50 \%$ of their original height at a compression rate of $5 \mathrm{~mm} / \mathrm{s}$ [16].

The object of modernization was a VOE.201 melon cleaning machine, assembled on the basis of LLC "Voplozhenie" (Moscow, Russian Federation). The machine is manufactured in the climatic version of UHL, category 4 according to GOST 15150-69 (Fig. 1). The modernization of the machine was carried out for cleaning the "Mirzachulskaya" melon variety grown in the southern regions of the Republic of Kazakhstan. At the initial stage, the machine was created for cleaning melons cultivated in the Krasnodar Territory (Russian Federation), in particular for the "Rainbow" variety melons. Both melon varieties are derived from the same genotype "Torpedo", but due to the difference in climate, soil and many other factors, the varieties have different morphology.

The operation principle of the VOE.201 melon cleaning machine is that the melon fruit is placed on the studded surface of the lower bed, the elasticity of which allows for its reliable contact with the fruit surface. In this case, the fruit is pre-pierced with needle clamps in the upper and lower parts of the fruit, which fixe it relative to the axis of rotation, and the working elements are brought in a horizontal direction to the fruit and provide contact of the cutting edges with the surface of the fruit peel. Then the rods are rotated in one direction from the drive. When the rods rotate, the cutting edge of the working element cuts into the peel and removes it in the form of chips. There is a layer-by-layer removal of the peel, by pressing the cutting edges with force, combined with ensuring a rational cutting force with a floating head. At the same time, the cutting depth is provided and limited by the force applied to the cutting surface, which, by dousing the fruit surface, provides a directional movement of the head, which ensures smooth and gentle processing of the fruit with high quality. After being completely peeled, the melon is removed for further processing.
Conventionally, there are two cutting methods: static (the cutting tool moves in the cutting direction) and sliding (the cutting tool moves in two mutually perpendicular directions parallel to the blade). A sliding cut is accompanied by a significant energy loss due to friction [17-19]. Along with the sliding movement, the concept of the sliding coefficient is introduced, as the ratio of the sliding speed of the blade relative to the material being cut to the feed speed. According to the literature, the cutting force depends on the slip coefficient along the cutting rods.

Depending on the sharpening angle of the wedge and its coefficient of friction on the material, the cutting process is significantly facilitated. However, the leading role is not given to the bevels, but to the direct impact of the blade edge on the material. This statement is true and is confirmed by many studies, but it should be noted that the influence of the blade on the parameters of the cutting process depends on the properties of the material being cut, the cutting method and other factors.

The percentage of melon peeling was calculated using the product weight before and after cleaning, as indicated below [20,21].

$$
y_{1}=\left(W_{1}-W_{2}\right) /\left(W_{1} \times t\right) \times 100,
$$

where $W_{2}$ must be zero or $W_{1}$. All the samples were weighed before $\left(W_{1}\right)$ and immediately after peeling $\left(W_{2}\right)$ on a scale with an accuracy of $\pm 1 \mathrm{~g}$.

After studying the texture properties of melons of two different varieties, experiments were conducted to determine the sharpening angle and the applied forces. The experiments were carried out on the VOE.201 melon cleaning machine using cutting knives of different sharpening angles, applying different forces. For the experiment, "Mirzachulskaya" variety melons of the 2020 harvest were taken.

The following factors have been determined for conducting experimental studies on melon peeling: knife sharpening angle $(A, \mathrm{grad})$, roller-cutting knife distance (gap) $(D, \mathrm{~mm})$ and efforts made to effectively separate the peel $\left(E, \mathrm{~N}^{*} \mathrm{~m}\right)$. All these factors mainly influence the optimization criterion - peel yield $(P, \%)$.

Next, we coded the variation intervals and levels of the parameters, which are presented in Table 1.

Table 1

Coding of variation intervals and levels of input factors

\begin{tabular}{|c|c|c|c|c|c|c|c|}
\hline \multirow{2}{*}{ Factors } & \multicolumn{5}{|c|}{ Variation levels } & $\begin{array}{c}\text { Variation } \\
\text { intervals }\end{array}$ \\
\hline Natural & Encoding & -1.68 & -1 & 0 & +1 & +1.68 & - \\
\hline$A, \mathrm{grad}$ & $x_{1}$ & 30 & 35 & 40 & 45 & 50 & 5 \\
\hline$D, \mathrm{~mm}$ & $x_{2}$ & 3 & 6 & 9 & 12 & 15 & 3 \\
\hline$E, \mathrm{~N}^{*} \mathrm{~m}$ & $x_{3}$ & 2,364 & 2369.5 & 2,375 & 2380.5 & 2,386 & 5.5 \\
\hline
\end{tabular}

The planning matrix is presented in Table 2 .

The experiments were conducted according to the planning matrix (Table 2). As an estimated indicator, data from the melon yield study produced by the calculation according to (2) were used.

To obtain a mathematical model of the melon peeling process, which is a regression equation, a second-order rotatable plan (Box plan) was used. It was based on 3 main factors, with 20 experiments, including 6 experiments at the zero point. To construct the regression equation, 10 coefficients are taken. 
Table 2

Matrix of melon cleaning experiments

\begin{tabular}{|c|c|c|c|c|c|c|}
\hline \multirow{2}{*}{ No. } & \multicolumn{3}{|c|}{ Encoded values } & \multicolumn{3}{c|}{ Natural values } \\
\cline { 2 - 7 } & $x_{1}$ & $x_{2}$ & $x_{3}$ & A, grad & $D, \mathrm{~mm}$ & $E, \mathrm{~N}^{*} \mathrm{~m}$ \\
\hline 1 & 2 & 3 & 4 & 5 & 6 & 7 \\
\hline 1 & - & - & - & 35 & 6 & 2369.5 \\
\hline 2 & - & - & + & 35 & 6 & 2380.5 \\
\hline 3 & - & + & - & 35 & 12 & 2369.5 \\
\hline 4 & - & + & + & 35 & 12 & 2380.5 \\
\hline 5 & + & - & - & 45 & 6 & 2369.5 \\
\hline 6 & + & - & + & 45 & 6 & 2380.5 \\
\hline 7 & + & + & - & 45 & 12 & 2369.5 \\
\hline 8 & + & + & + & 45 & 12 & 2380.5 \\
\hline 9 & -1.68 & 0 & 0 & 30 & 9 & 2,375 \\
\hline 10 & +1.68 & 0 & 0 & 50 & 9 & 2,375 \\
\hline 11 & 0 & -1.68 & 0 & 40 & 3 & 2,375 \\
\hline 12 & 0 & +1.68 & 0 & 40 & 15 & 2,375 \\
\hline 13 & 0 & 0 & -1.68 & 40 & 9 & 2,364 \\
\hline 14 & 0 & 0 & +1.68 & 40 & 9 & 2,386 \\
\hline 15 & 0 & 0 & 0 & 40 & 9 & 2,375 \\
\hline 16 & 0 & 0 & 0 & 40 & 9 & 2,375 \\
\hline 17 & 0 & 0 & 0 & 40 & 9 & 2,375 \\
\hline 18 & 0 & 0 & 0 & 40 & 9 & 2,375 \\
\hline 19 & 0 & 0 & 0 & 40 & 9 & 2,375 \\
\hline 20 & 0 & 0 & 0 & 40 & 9 & 2,375 \\
\hline
\end{tabular}

Technological indicators of the melon peeling process are accepted as optimality criteria that determine specific production conditions. Therefore, it was advisable to adjust the system of regression equations in accordance with these factors. The general view of the regression equation is as follows:

$$
\begin{aligned}
& y_{1}=b_{0}+b_{1} x_{1}+b_{2} x_{2}+b_{3} x_{3}+b_{12} x_{1} x_{2}+ \\
& +b_{13} x_{1} x_{3}+b_{23} x_{2} x_{3}+b_{11} x_{1}^{2}+b_{22} x_{2}^{2}+b_{33} x_{3}^{2} .
\end{aligned}
$$

\section{Here:}

$x_{1}$ - knife sharpening angle ( $A$, grad);

$x_{2}$ - roller-cutting knife distance (gap) $(D, \mathrm{~mm})$;

$x_{3}$ - efforts made to effectively separate the peel $\left(E, \mathrm{~N}^{*} \mathrm{~m}\right)$;

$b$ - optimization criterion - peel yield $(P, \%)$.

The efficiency of the developed equipment is calculated and determined using linear mathematical modeling. As a result, optimal options for cutting and cleaning melons were determined.

As a mathematical tool, we use mathematical and statistical methods and get a system of regression equations that models the relationship of the most preferred optimality criterion with the rest.

\section{Results of research of melon cleaning and development of a mathematical model}

\subsection{Results of the study of the melon texture prop-} erties

When studying the texture properties of melons, of great importance for determining the yield of melon products is the ratio of the parts that make up the fruit: pulp, peel, seeds, and placenta. The obtained data for melons of the "Mirzachulskaya" and "Raduzhnaya" varieties are shown in Fig. 1.

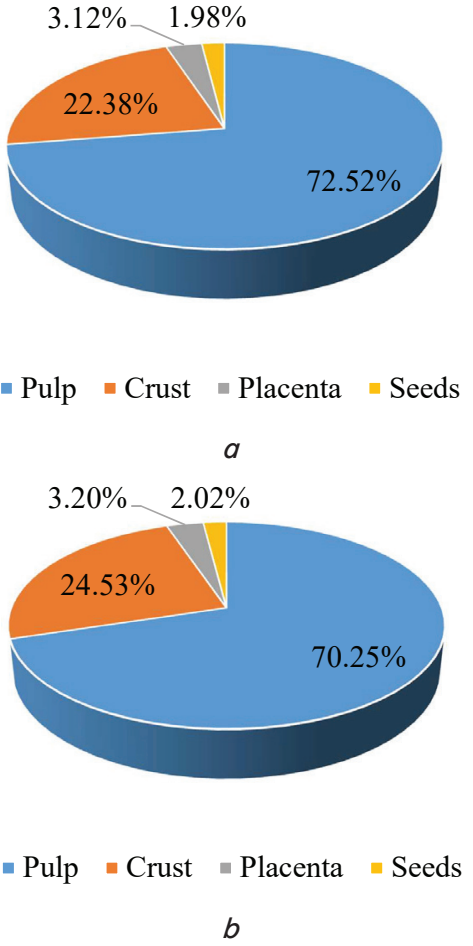

Fig. 1. Yield of components when cutting melon fruits: $a$ - "Mirzachulskaya" variety; $b$ - "Raduzhnaya" variety

From Fig. 1, it follows that a pulp yield for the "Mirzachulskaya" variety is $72.52 \%$, peel $-22.38 \%$. The "Rainbow" variety has a pulp yield of $70.25 \%$, and peel $-24.53 \%$. From this, the pulp yield will be greater in the "Mirzachulskaya" variety, and it also has the thinnest peel compared to the "Rainbow" variety. The seed content in the "Mirzachulskaya" and "Raduzhnaya" varieties is 1.98 and $2.02 \%$, respectively. The dependence of the seed content on which class of melons belongs to the maturation period is not observed. This indicator depends only on the characteristics of the variety, since both of these varieties come from the same genotype, the prevalence of this indicator is insignificant.

The density of the pulp is important in determining the peeling effort. The results obtained for determining the density of the layer adjacent to the peel and the inner part of the melon of the two varieties are shown in Fig. 2.

The experimental results indicate that the melon density for both varieties is not the same throughout the entire volume of the fruit and there is a decrease from the layers adjacent to the peel to the inner layers, however, the "Mirzachulskaya" variety in some places has less dense pulp - 1.4; $1.29 ; 1.25 \mathrm{~kg} / \mathrm{m}^{3}$ in the adjacent, middle and inner layers, respectively. For the "Raduzhnaya" variety, this indicator is $1.42 ; 1.3$ and $1.2 \mathrm{~kg} / \mathrm{m}^{3}$.

When obtaining products from melon pulp, the determining properties are the specific cutting force, the modulus of volumetric elasticity and the effective viscosity of the pulp. The first indicator is also important when calculating the drive power, especially when separating it from the belt or cutting device. The results of studies on the specific cutting force and its average values are presented in Table 3.

The obtained data indicate that the values of the specific forces of slicing melon pulp layers for the "Mirzachulskaya" and "Raduzhnaya" varieties are $206 \mathrm{~N} \cdot \mathrm{m}$ and $208 \mathrm{~N} \cdot \mathrm{m}$, respectively. The values of the specific forces of slicing the peel when separating it from the pulp for "Mirzachulskaya" 
are 2,386 N.m and 2,364 N.m for "Raduzhnaya". In addition, the deviation from the average cutting force for individual grades does not exceed $(-3.18 \% \ldots+3.2 \%)$ for the pulp and $(-1.10 \% \ldots+1.20 \%)$ for the peel.

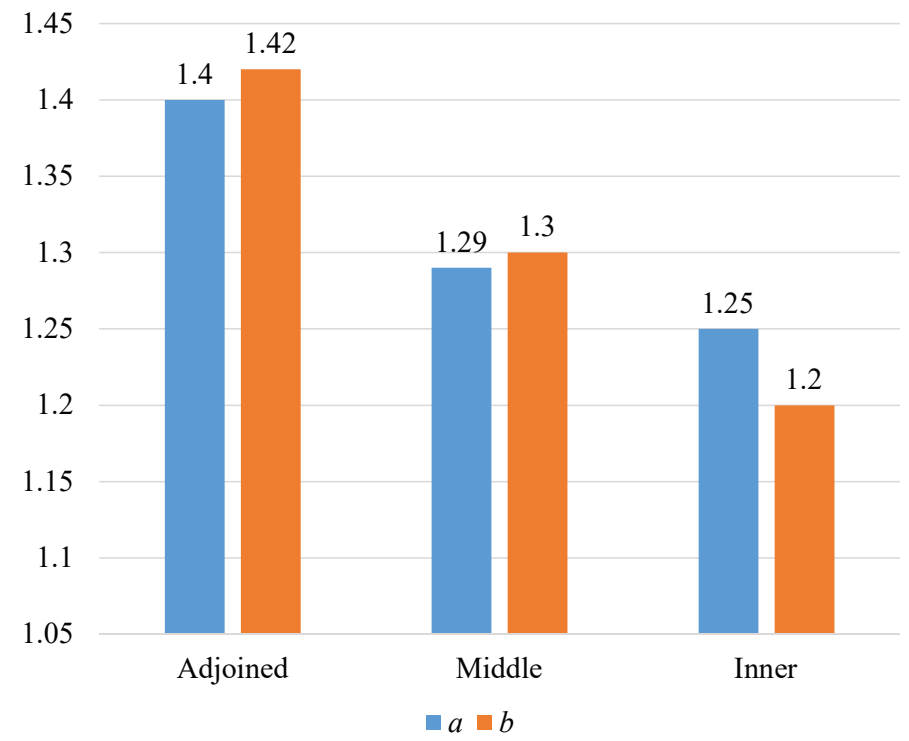

Fig. 2. Melon pulp density: $a-$ "Mirzachulskaya" variety; $b$ - "Raduzhnaya" variety

Table 3

Melon cutting force values

\begin{tabular}{|c|c|c|c|}
\hline \multirow{2}{*}{ No. } & \multirow{2}{*}{ Variety } & \multicolumn{2}{|c|}{ Specific cutting force, $\mathrm{N} \cdot \mathrm{m}$} \\
\cline { 3 - 4 } & & Pulp & Peel \\
\hline 1 & Mirzachulskaya & 206 & 2,386 \\
\hline 2 & Kolkhoznitsa & 208 & 2,364 \\
\hline 3 & Average value & $216.5 \%$ & 2,375 \\
\hline 4 & Greater deviation & $+3.2 \%$ & $+1.10 \%$ \\
\hline 5 & Smaller deviation & $-3.18 \%$ & $-1.20 \%$ \\
\hline
\end{tabular}

Thus, the conducted studies allow us to conclude that the average values of the specific cutting force for the studied melon varieties have an error not exceeding $3.2 \%$ for the pulp and $2.3 \%$ for the peel.

\section{2. Melon cleaning equipment, study of the peeling} mechanism

In the course of research on production and design flaws, identification of weaknesses and shortcomings of equipment, it was found that the most inappropriate knot is a knife. Initially, this equipment (Fig. 3) was designed for the "Raduzhnaya" melon variety, respectively, the knives were sharpened for its morphological and textural properties. Although melons of both varieties belong to the same genotype, they have different properties, this was clarified in Section 5. 1.

When cutting without sliding, the influence of the blade on the cutting process is reduced, the sharpening angles, thickness and shape of the knife become decisive.

When cutting with sliding, the material particles in the area of direct contact with the blade during compression are captured by the irregularities of the blade and are displaced in the direction of sliding. Due to this, tangential stresses occur between the displaced and connected particles instead of normal ones. As a result, the nature of material destruction changes and instead of compression, another type of destruc- tion occurs, tearing or shifting of the particles. The latter occurs at significantly lower destructive stresses. Cutting with a knife, when its speed is directed along the blade, is sometimes called "sawing". This ensures a high-quality cut.

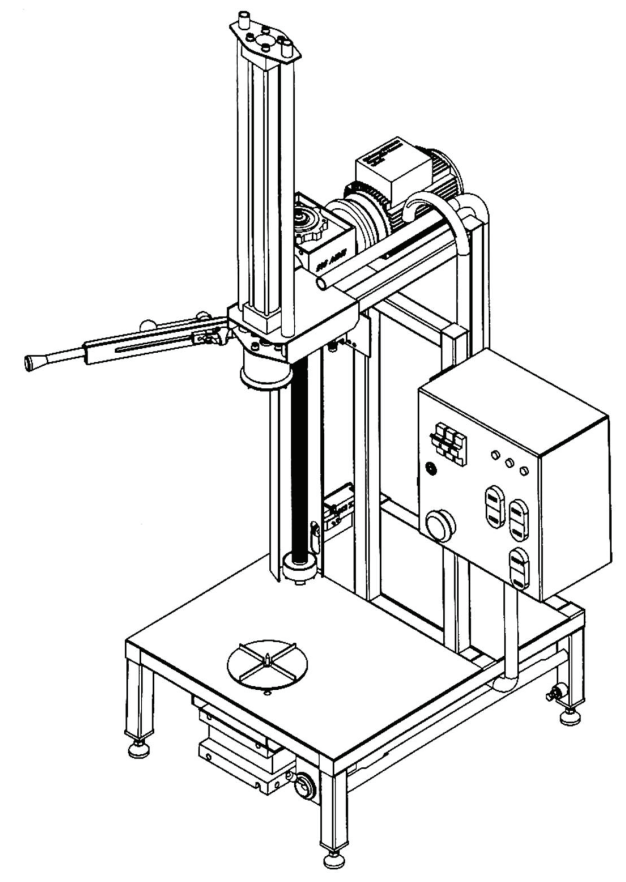

Fig. 3. VOE. 201 melon cleaning machine

Sharpening of knives was carried out from the lateral outer side, to ensure the discharge of the separated melon peel to the side.

\section{3. Building a mathematical model for melon cleaning}

Based on the data of the conducted experiments, a mathematical model was constructed (Fig. 4). A regression equation was also obtained, which helps to calculate the optimal parameters of the indicators when their values change:

$$
\begin{aligned}
& y_{1}=21.40118752-0.43627 x_{1}-0.4187 x_{2}- \\
& -0.17275 x_{3}-0.125 x_{1} x_{2}-0.625 x_{1} x_{3}- \\
& -0.125 x_{2} x_{3}-0.60624 x_{1}^{2}+0.62856 x_{2}^{2}+98136 x_{3}^{2},
\end{aligned}
$$

Here:

$x_{1}$ - knife sharpening angle $(A$, grad);

$x_{2}$ - roller-cutting knife distance (gap) $(D, \mathrm{~mm})$;

$x_{3}$ - efforts made to effectively separate the peel $(E, \mathrm{~N} \cdot \mathrm{m})$.

The equation shows the dependences of the knife sharpening angle, roller-cutting knife distance and force applied to effectively separate the peel on the peel yield (optimization criterion).

The three-dimensional model makes it clear that each factor is equally important for performing the melon cleaning process.

Fig. 4 shows a three-dimensional model in space, characterizing separately the dependence of different parameters: Fig. 4, $a$ shows the dependence of the knife sharpening angle on the roller-cutting knife distance; Fig. 4, $b$ shows the dependence of the knife sharpening angle on the cutting force; Fig. 4, $c$ shows the dependence of the roller-knife distance on the cutting force. 


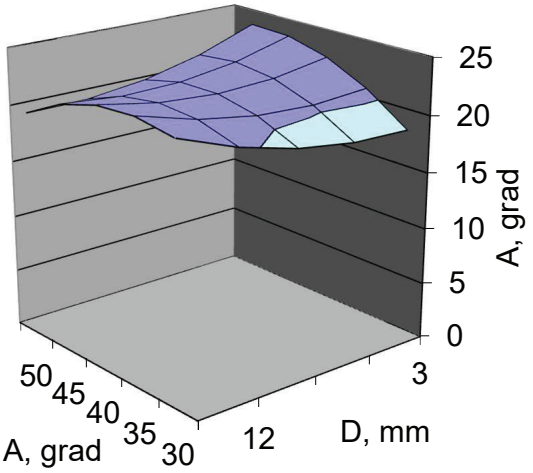

$a$
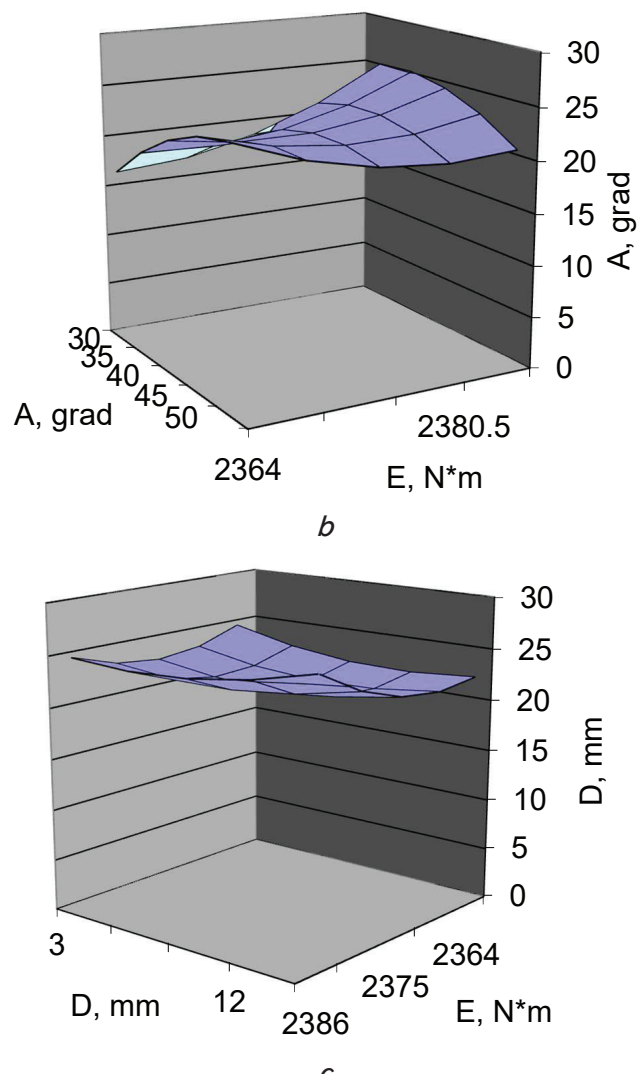

Fig. 4. Three-dimensional model in space that characterizes the dependence: $\mathrm{x}_{n}=f(a, b, c)$ in $\mathrm{y}_{n}=f(\mathrm{P})$, here: $a$ - effect of knife sharpening angle $(A, \mathrm{grad})$ and roller-cutting knife distance $(D, \mathrm{~mm}), b$ - effect of knife sharpening angle $(A, \mathrm{grad})$ and cutting forces $(E, \mathrm{~N} \cdot \mathrm{m}), c-$ effect of roller-cutting knife distance $(D, \mathrm{~mm})$ and cutting forces $(E, \mathrm{~N} \cdot \mathrm{m})$

In the course of optimizing the parameters for effective melon peeling, the knife sharpening angle is of particular interest, as a characteristic that determines one of the main parameters. From Fig. 4, it can be seen that the sharper the knife and the larger (wider) the roller-knife gap, the greater the loss. This means that the entire optimization process is focused on achieving this peeling indicator. If the sharpening angle is increased to 50 degrees, the knife is blunter, and removes the peel not effectively, leaving its inner layers.

The main peak of losses occurred when the indicators of the sharpened knife were up to 30 degrees and with a maximum effort of $2386 \mathrm{~N} \cdot \mathrm{m}$, removing $30 \%$ (Fig. $4, b$ ). That is, with a peel yield of $22.38 \%$, the loss of the required raw material was $7.62 \%$.

Fig. 4, $c$ shows the effect of the force and roller-knife gap on peeling. With this comparison, you can see that with the maximum effort applied, regardless of the roller gap and its resistance, the knife rushes so deep into the pulp, cutting off its valuable part. While at the minimum values, the cutting of the peel is less effective.

Thus, from the model given in Fig. 4, it follows that the optimal melon peeling parameters fall on the peeling rate of $22.5 \%$. The optimal sharpening angle of the cutting knife will be 40 degrees with a roller gap width of $9 \mathrm{~mm}$, as well as with an average force applied of $1375 \mathrm{~N} \cdot \mathrm{m}$.

The results of experimental data indicate that the melon density for both varieties is not the same throughout the entire volume of the fruit and there is a decrease from the layers adjacent to the peel to the inner layers, however, the "Mirzachulskaya" variety in some places has a less dense pulp - 1.4; $1.29 ; 1.25 \mathrm{~kg} / \mathrm{m}^{3}$ in the adjacent, middle and inner layers, respectively. For the "Raduzhnaya" variety, this indicator is $1.42 ; 1.3$ and $1.2 \mathrm{~kg} / \mathrm{m}^{3}$.

When determining the optimal melon peeling parameters, the speed of the tray with the melon was not taken into account, since this is not the main indicator of cleaning efficiency.

The results showed that these peeling equipment and technology help to reduce energy consumption by 2 times and increase the yield of products.

\section{Discussion of experimental results of studying the process and modes of melon cleaning on the modernized machine}

The literature review showed that the existing technologies and methods of melon cleaning do not satisfy producers' needs, increase the cost of production, raw materials and obtained products substantially. Therefore, the scientists reconstructed the VOE.201 melon cleaning machine by modernizing the cutting tool in order to eliminate these problems. The modernization of the existing technique was carried out by changing the sharpening angle of the peel cutting knife. Also on this cleaning machine, melons of the "Mirzachulskaya" and "Raduzhnaya" varieties were cleaned and their textural properties were investigated. Optimal melon peeling modes have been calculated using mathematical modeling. Based on the experiments, a model of the peeling process was constructed (3). For optimization, 3 input parameters were taken: knife sharpening angle, forces applied to the knife and knife-roller gap. Since the speed was constant, it was not taken into account.

The main difficulty in melon peeling is poor automation, as well as versatility of the equipment. It is necessary to continue modernizing the equipment until full versatility is achieved through the introduction of interchangeable knives designed for various varieties and types of crop products, as well as clear instructions with well-established modes for these knives.

In the course of the experiment, the textural properties of two "Mirzachulskaya" and "Raduzhnaya" melon varieties were studied, the operation of a modernized melon peeling machine was analyzed and the peeling mechanism was stud- 
ied, a mathematical model for melon cleaning was also built and optimal cleaning modes were determined.

The introduction of our modernized cleaning machine is beneficial for production, shortens the cleaning process and reduces the loss of melon nutrients, while increasing the production profit. The installation differs from other analogs in its low cost, simplified technology and environmental friendliness.

\section{Conclusions}

1. Studies of the textural properties of the "Mirzachulskaya" and "Raduzhnaya" melon varieties showed that the pulp content is $72.52 \%$ and $70.25 \%$, and peel $-22.38 \%$ and $24.53 \%$. Experimental data from studying the melon density in different parts amounted to $1.4 ; 1.29 ; 1.25 \mathrm{~kg} / \mathrm{m}^{3}$ for the "Mirzachulskaya" variety and 1.42; 1.3 and $1.2 \mathrm{~kg} / \mathrm{m}^{3}$ for the "Raduzhnaya" variety. Specific efforts of cutting melon pulp layers for the "Mirzachulskaya" and "Raduzhnaya" varieties are $206 \mathrm{~N} \cdot \mathrm{m}$ and $208 \mathrm{~N} \cdot \mathrm{m}$, respectively. The values of the specific pell cutting efforts when separating it from the pulp for the "Mirzachulskaya" variety are 2,386 N.m and 2,364 N.m for the "Raduzhnaya" variety.

2 . When studying the operation principle of the VOE.201 melon peeling machine, assembled on the basis of LLC "Voplozhenie" (Moscow, Russian Federation), it was found that, when the rolls rotate, the cutting edge of the working element cuts into the peel of the fruit and removes it in the form of shavings. It was determined that the most adjustable parameters are the force applied to the knife and the sharpening angle of the knife, that is, the cutting element. The main focus of the study is on changing the knife sharpening angle. For the knife of the melon peeling machine, sharpening was carried out from the lateral outer side, to ensure the discharge of the melon peel to the side. As a result, the nature of material destruction changes and instead of compression, another type of destruction occurs, breaking or shearing of the particles. The knife showed an efficiency of $98 \%$.

3. The optimized parameters were the knife sharpening angle of 40 degrees with a roll gap of $9 \mathrm{~mm}$, as well as with an average applied force of $1,375 \mathrm{Nm}$.

\section{References}

1. Mallek-Ayadi, S., Bahloul, N., Kechaou, N. (2017). Characterization, phenolic compounds and functional properties of Cucumis melo L. peels. Food Chemistry, 221, 1691-1697. doi: https://doi.org/10.1016/j.foodchem.2016.10.117

2. Maietti, A., Tedeschi, P., Stagno, C., Bordiga, M., Travaglia, F., Locatelli, M. et. al. (2012). Analytical Traceability of Melon (Cucumis Melo Var Reticulatus): Proximate Composition, Bioactive Compounds, and Antioxidant Capacity in Relation to Cultivar, Plant Physiology State, and Seasonal Variability. Journal of Food Science, 77 (6), C646-C652. doi: https://doi.org/10.1111/ j.1750-3841.2012.02712.x

3. Rodríguez-Pérez, C., Quirantes-Piné, R., Fernández-Gutiérrez, A., Segura-Carretero, A. (2013). Comparative characterization of phenolic and other polar compounds in Spanish melon cultivars by using high-performance liquid chromatography coupled to electrospray ionization quadrupole-time of flight mass spectrometry. Food Research International, 54 (2), 1519-1527. doi: https:// doi.org/10.1016/j.foodres.2013.09.011

4. Pitrat, M. (2013). Phenotypic diversity in wild and cultivated melons (Cucumis melo). Plant Biotechnology, 30 (3), 273-278. doi: https://doi.org/10.5511/plantbiotechnology.13.0813a

5. Cui, H., Ding, Z., Zhu, Q., Wu, Y., Qiu, B., Gao, P. (2021). Comparative analysis of nuclear, chloroplast, and mitochondrial genomes of watermelon and melon provides evidence of gene transfer. Scientific Reports, 11 (1). doi: https://doi.org/10.1038/s41598-02080149-9

6. Schmilovitch, Z., Alchanatis, V., Ignat, T., Hoffman, A., Egozi, H., Ronen, B. et. al. (2015). Machinery for Fresh Cut Watermelon and Melon. Chemical engineering transactions, 44, 277-282. doi: https://doi.org/10.3303/CET1544047

7. Oluwabamiwo, F., Adegoke, G., Denloye, S., Akinoso, R. (2015). Proximate composition and fatty acid profile of Nigerian melon seeds. Life Science Archives, 1, 59-65.

8. Erdogan, F., Turkmen, O. (2020). Morphological characterization of the local melon genotypes of lake zone in Turkey. Fresenius Environmental Bulletin, 29 (11), 9621-9626.

9. Toker, İ., Bayundurl, A. (2003). Enzymatic peeling of apricots, nectarines and peaches. LWT - Food Science and Technology, 36 (2), 215-221. doi: https://doi.org/10.1016/s0023-6438(02)00203-7

10. Emadi, B., Abbaspour-Fard, M. H., Yarlagadda, P. (2009). Mechanical Properties of Melon Measured by Compression, Shear, and Cutting Modes. International Journal of Food Properties, 12 (4), 780-790. doi: https://doi.org/10.1080/10942910802056143

11. Singh, K. K., Shukla, B. D. (1995). Abrasive peeling of potatoes. Journal of Food Engineering, 26 (4), 431-442. doi: https://doi.org/ 10.1016/0260-8774(94)00065-h

12. Tapia, M. R., Gutierrez-Pacheco, M. M., Vazquez-Armenta, F. J., González Aguilar, G. A., Ayala Zavala, J. F., Rahman, M. S., Siddiqui, M. W. (2014). Washing, Peeling and Cutting of Fresh-Cut Fruits and Vegetables. Minimally Processed Foods, 57-78. doi: https:// doi.org/10.1007/978-3-319-10677-9_4

13. Mayobre, C., Pereira, L., Eltahiri, A., Bar, E., Lewinsohn, E., Garcia-Mas, J., Pujol, M. (2021). Genetic dissection of aroma biosynthesis in melon and its relationship with climacteric ripening. Food Chemistry, 353, 129484. doi: https://doi.org/10.1016/ j.foodchem.2021.129484 
14. Davies, R. M. (2010). Engineering Properties of Three Varieties of Melon Seeds as Potentials for Development of Melon Processing Machines. Advance Journal of Food Science and Technology, 2 (1), 119-127. Available at: https://agris.fao.org/agris-search/ search.do? recordID=DJ2012046334

15. Bourne, M. C. (1978). Texture profile analysis. Food Technology, 32. Available at: https://www.researchgate.net/ publication/284667923_Texture_Profile_Analysis

16. Iztayev, A., Kulazhanov, T. K., Yakiyayeva, M. A., Zhakatayeva, A. N., Baibatyrov, T. A. (2021). Method for the safe storage of sugar beets using an ion-ozone mixture. Acta Scientiarum Polonorum Technologia Alimentaria, 20 (1), 25-35. doi: https://doi.org/ 10.17306/j.afs.0865

17. Lázaro, A., de Lorenzo, C. (2015). Texture Analysis in Melon Landraces through Instrumental and Sensory Methods. International Journal of Food Properties, 18 (7), 1575-1583. doi: https://doi.org/10.1080/10942912.2014.923441

18. Trollope, J. R. (1982). A mathematical model of the threshing process in a conventional combine-thresher. Journal of Agricultural Engineering Research, 27 (2), 119-130. doi: https://doi.org/10.1016/0021-8634(82)90098-1

19. Zhakatayeva, A., Iztayev, A., Muldabekova, B., Yakiyayeva, M., Hrivna, L. (2020). Scientific security assessment of safety risk of raw sugar products. Periódico Tchê Química, 17 (34), 352-368.

20. Tanaka, K., Akashi, Y., Fukunaga, K., Yamamoto, T., Aierken, Y., Nishida, H. et. al. (2013). Diversification and genetic differentiation of cultivated melon inferred from sequence polymorphism in the chloroplast genome. Breeding Science, 63 (2), 183-196. doi: https://doi.org/10.1270/jsbbs.63.183

21. Akhoundnejad, Y., Dasgan, H. Y. (2020). Photosynthesis, transpiration, stomatal conductance of some melon (Cucumic melo L.) genotypes under different drought stress. Fresenius Environmental Bulletin, 29 (12), 10974-10979. 